Cad.Est.Ling., Campinas, 47(1) e (2):11-15, 2005

\title{
SOBRE O PROJETO DE AQUISIÇÃO DE LINGUAGEM E E A OBRA DE SUA FUNDADORA: UMA HOMENAGEM A CLÁUDIA LEMOS
}

\author{
MARIA FAUSTA PEREIRA DE CASTRO $^{1}$
}

Prezados Senhores Professores que compõem esta mesa de abertura: Dr ${ }^{\mathrm{a}}$ Cláudia Thereza Guimarães de Lemos, Dr. José Tadeu Jorge, vice-reitor da UNICAMP, Dr. Luiz Carlos da Silva Dantas diretor do IEL, Dr ${ }^{a}$ Charlotte Galves chefe do Departamento de Linguistica, Dr ${ }^{a}$ Mônica Zoppi-Fontana, coordenadora do programa de Pós-Graduação do DL. Caros convidados, colegas, alunos e funcionários.

Junto com o IEL, O PROJETO DE AQUISIÇÃO DE LINGUAGEM, fundado e coordenado pela professora Cláudia Lemos e composto de uma equipe de pesquisadoras interessadas no estudo da fala da criança completa, neste ano, 25 anos de sua fundação.

Considerando a inegável importância que o Projeto conquistou ao longo dos anos de sua existência, do debate científico por que foi responsável e por seu papel de impulsionador da pesquisa em aquisição de linguagem no Brasil, acreditamos que não se deveria deixar passar em branco este momento em que a história reune a fundação do Projeto e a do próprio IEL.

Com este Seminário que hoje abrimos criamos a ocasião para homenagear a professora Cláudia Lemos, pelo seu trabalho de pesquisa em aquisição de linguagem, área que marcou com uma reflexão rigorosa e original, pontuada pelo reconhecimento crescente da resistência que a fala da criança oferece ao investigador que a constitui como uma empiria a ser descrita pela lingüística.

Em recente artigo publicado nos Cadernos de Estudos Lingüísticos, Cláudia Lemos refere-se ao início do seu trabalho na área, momento em que, orientada pelo professor John Lyons, defendeu uma tese de doutorado sobre a oposição entre ser e estar em sentenças locativas, com o foco na aquisição de linguagem, como um primeiro passo para uma interrogação sobre a fala da criança. Seu olhar crítico atual não vê alí senão uma procura do conhecimento da língua pela criança, em que a fala não passava "de direta e inquestionável evidência desse conhecimento" (Lemos, C.T. 2002:42). Mesmo o fato de ter alcançado um grau de formalização de sua hipótese, segunda ela, não serviu de mediação teórica para chegar à fala da criança.

\footnotetext{
${ }^{1}$ fausta@uol.com.br.
} 
Se, por um lado, a heterogeneidade desta fala e a impossibilidade de encontrar um modelo que a regularizasse numa ordem de desenvolvimento foram os pontos de resistência, por outro, estas questões foram também o móvel de um Projeto, que se deve agora entender não apenas como aquele cujos 25 anos hoje comemoramos, mas também como uma trajetória de trabalho em que se formulam e reformulam os modos de aproximação e teorização da fala da criança.

Com a volta ao Brasil e a contratação pela UNICAMP, surge a possibilidade da formação de um grupo de pesquisa com investigadoras que alí iniciariam suas teses de doutorado. Rosa Attié Figueira, Ester Scarpa já eram professoras do Departamento de Lingüística, pertencente ao Instituto de Ciências Humanas e, naquele momento, passando a constituir o recém-fundado Instituto de Estudos da Linguagem. Maria Cecilia Perroni, que acabara de defender sua tese de mestrado em aquisição da morfologia verbal, sob a orientação de Carol Stoel, é contratada, pela indicação de Cláudia Lemos, para integrar o quadro do Projeto. Minha contratação é simultânea a esse período de efervescência acadêmica e, em pouco tempo, já trabalhávamos na redação de um Projeto de Pesquisa, que recebeu apoio da FAPESP, conquista então inédita para a área das ciências humanas. Com o auxílio da FAPESP foi possível comprar equipamento e outros materiais para gravar semanalmente crianças, da idade de um ano até a de cinco, em interação com a mãe, outros membros da família e uma ou duas das investigadoras. $O$ acervo que resultou deste monumental trabalho está hoje no Centro de Documentação Alexandre Eulálio e é composto de centenas de fitas gravadas e 505 sessões já transcritas, estando estes dados entre os mais consultados até hoje no CEDAE. Basta mencionar o fato de as três concorrentes ao Prêmio Alexandre Eulálio de Monografia do ano de 2001 elaborarem seus trabalhos a partir de dados do Projeto.

O texto enviado à FAPESP é hoje um documento importante para se considerarem as questões teóricas que sustentavam o debate da época, mas também para compreender o modo de inserção do Projeto neste debate. Se o seu título - "Relações entre desenvolvimento cognitivo e desenvolvimento pré-lingüístico e lingüístico em crianças brasileiras" - mostra sem rodeios a presença dominante da psicologia na aquisição de linguagem naquele momento, a leitura do texto revela a cautela e o alerta sobre os equívocos que se podiam originar de uma utilização de modelos psicológicos associados a modelos lingüísticos em estudos sobre aquisição de linguagem.

Cláudia Lemos, no artigo que mencionei há pouco, considera que se levantaram duas barreiras ao possível distanciamento do lingüístico que a busca de relações entre desenvolvimento cognitivo e lingüístico poderia acarretar : primeiro o fato "de a questão que inspirou o Projeto - a fala da criança e o quantum de lingüístico que se podia e se devia atribuir a ela - ter-se mantido como eixo da interpretação e do desejo de teorização". Segundo, o fato de as pesquisadoras que nele se engajaram para a elaboração de suas teses de doutorado serem ou lingüistas efetivamente voltadas para o lingüistico ou uma psicóloga realmente interessada em linguagem. Eu acrescentaria a estas duas barrreiras uma terceira, motivada pelo próprio ambiente de vivo debate que se desenrolava entre alunos e professores do IEL e os seminários de filosofia da linguagem com colegas do próprio Instituto e do Centro de Lógica e Epistemologia e História da Ciência (CLE), que incentivavam a interrogação dos modelos psicológicos vigentes e a fidelidade à fala da criança. 
Cadernos de Estudos Lingüísticos 47(1) e (2) - Jan./Dez. 2005

O mérito que hoje se acrescenta ao nome de Cláudia Lemos decorre de um longo percurso, de vários fatores, dentre eles o fato de ela ter podido constituir um grupo de pesquisa, mas sobretudo pela sua capacidade de levar a frente uma reflexão que manteve independência, sem perder de vista o debate contemporâneo. Por isso, ainda que o Projeto não exista mais como grupo e que seus membros fundadores tenham atualmente orientações diversas, muitos foram os pesquisadores que diretamente orientados por ela ou motivados pela sua reflexão, souberam reconhecer a abrangência e a pertinência de suas hipóteses sobre a fala da criança.

Dentre os marcos teóricos a se assinalarem destaco inicialmente a noção de processos dialógicos que nasceu com preocupações descritivo-metodológicas, a partir de uma forte evidência extraída dos dados do Projeto. A ancoragem da fala da criança na fala do adulto, principalmente na fala da mãe, e os enunciados com que esta interpretava choro, gestos ou fala fragmentada da criança, promoviam um efeito de coesão e progressão dialógicas, em que a autora reconheceu tanto a desigualdade dessa interação quanto " a conexão de natureza lingüística" que ela produzia.

Note-se que a noção de processos dialógicos produziu também seus efeitos de ancoragem, já que podemos contar inúmeros trabalhos que a tomaram como lugar de inserção teórico-metodológica para a análise de diferentes fatos ligados à aquisição de linguagem e outros, mais recente, que se detiveram na análise da própria noção destes processos, de sua abrangência e limite.

O outro ponto a se destacar não é independente do primeiro; ao contrário, reconhecendo na discussão empreendida sobre a relação entre a criança e o outro, a sua fala, e a língua a presença do sujeito da psicologia e ainda a impossibilidade, naquele momento, de tratar ao mesmo tempo do outro e da língua, mas também ciente de quanto o seu trabalho diferia daqueles que se alinhavam ao modelo sócio-cronstrutivista, Cláudia Lemos inicia um processo de mudança teórica que opera na explicitação das diferenças entre os dois pontos de vista, o que promoveu um afastamento mais radical da psicologia do desenvolvimento e uma insistência na lingüística. Tome-se contudo esta insistência em termos muito diferentes daqueles que caracterizaram o primeiro momento da sua relação com a aquisição de linguagem. Trata-se agora de uma leitura que vem marcada pelo encontro com a psicanálise lacaniana, o que muda o rumo a tomar.

De fato, o artigo sobre os processos metafóricos e metonímicos - apresentado em um Simpósio Internacional sobre Mecanismos de Mudança, organizado pela Universidade de Barcelona - representou ao mesmo tempo uma crítica à teoria do desenvolvimento, vigente tanto nos aquisicionistas como na psicologia, e uma releitura de Saussure, Jakobson, que sustentavam esta crítica.

A partir deste momento uma rica atividade intelectual se manifesta através de inúmeros artigos, que aos poucos delineiam o caminho para uma visão estrutural da mudança. Ela fala de aquisição, mas também, da obra de Saussure, das relações da lingüística com outras ciências, sobre língua e discurso e ainda sobre poética. Sempre lendo e relendo Saussure, Jakobson, Chomsky, Jean Claude Milner e um contato a cada tempo mais estreito com a obra de Jacques Lacan conduzem-na à procura, "de uma definição mais clara do sujeito que seria compatível com a concepção de língua na teorização da lingüística". 
Com originalidade e precisão Cláudia parte do fato de que aquilo que Saussure nomeou ordem própria da língua está na origem dos dois projetos da constituição da lingüística como ciência, isto é, tanto no projeto estruturalista representado pela obra do próprio Saussure quanto no projeto gerativista, cujos fundamentos se encontram na obra de Chomsky. Na releitura deste último ela se pergunta com ele, indicando ao mesmo tempo seu próprio caminho teórico: dada a não observabilidade das propriedades lingüísticas e de uma conseqüente impossibilidade delas serem apreendidas e aprendidas pela generalização indutiva, como se deve supor essa criança que adquire a linguagem? $\mathrm{Ou}$, explicitando sua própria questão: que sujeito está aí implicado?

Na esteira desta reflexão, que caminha no sentido oposto à solução dada por Chomsky ao que ele formulou como o dilema de Platão, passa a considerar a língua, enquanto alteridade radical, pela sua função de captura, conceito que condensa a inversão da relação sujeito-objeto da psicologia do desenvolvimento e que lhe permite conceber a criança como capturada por um funcionamento lingüístico-discursivo e as mudanças que caracterizam sua trajetória de infans a sujeito-falante como mudanças de posição relativamente ao outro, à língua e, em consequiência à sua própria fala. Em um segundo momento, sobretudo em trabalhos dos dois últimos anos, a mudança se define como mudança de posição em uma estrutura, no sentido em que não há superação de nenhuma das três posições acima referidas, mas um modo de articulação entre elas em diferentes momentos da cronologia do processo. Com a elaboração deste modo de articulação, segundo Cláudia - passo a citá-la - "pretendia-se, assim, atingir o objetivo maior de explicar as mudanças de posição a partir do efeito do funcionamento da língua, funcionamento esse que, do ponto de vista da criança enquanto nele inserida, não seria (...) apreendido pela descrição de seus enunciados, e sim pelos processos metafóricos e metonímicos (op. cit:56)".

Esta súmula, costurada a ponto largo, de parte da história acadêmica da professora Cláudia, e de sua reflexão sobre a fala da criança, não poderia deixar de incluir outro fato que se relaciona de modo diverso com esta história e reflexão. Trata-se da formação clínica a que ela vem se submetendo concomitantemente ao estudo sistemático da obra de Lacan e da atividade clínica que deles decorre, cuja repercussão já começa a se fazer sentir de modo mais explícito nos seus dois últimos trabalhos - "Das vicissitudes da fala da criança e de sua investigação" e "Sobre fragmentos e holófrases". Neles se estende claramente o que até então a Cláudia via como possibilidade de uma relação entre Lingüística e a Psicanálise no campo da aquisição de linguagem.

O Seminário que hoje abrimos, como comemoração, não se afasta do que bem conhecemos de um evento acadêmico. Nestes três dias serão apresentados e debatidos trabalhos cujos autores são filiados ao projeto pelo vínculo acadêmico ou pelos desdobramentos teóricos e temáticos gerados nestes anos de convivência e debate, que devem muito à reflexão da Cláudia.

Se hoje não há mais o Projeto nos termos em que foi fundado, nunca se deixou, porém, de levar a frente, com entusiasmo, as pesquisas sobre a aquisição de linguagem, a fala da criança, e posteriormente, sobre a escrita inicial. Livros, artigos, teses, participações em congressos, organização de seminários no período entre 1989-1993, debates, cursos, e outros grupos que se constituíram no Instituto para estudar por ângulos distintos a fala da 
Cadernos de Estudos Lingüísticos 47(1) e (2) - Jan./Dez. 2005

e escrita da criança, são prova de que o IEL, em momento algum de sua história, deixou de lado a reflexão sobre o fenômeno da aquisição de linguagem

Não poderia deixar de mencionar, antes de terminar esta saudação, o nome das crianças, hoje jovens adultos, que participaram das incontáveis sessões de gravação e que com suas falas infantis nos interrogam até hoje. São eles: Renata, Augusto, Raquel, Tiago, Ana Maria, Daniela, Carina e Veronica.

Agradecemos à Cláudia Lemos por ter tornado este trabalho possível. Agradeço também a todos que responderam com sua presença ao convite para esta homenagem e peço-lhes agora uma salva de palmas para nossa homenageada. 